\title{
PHARMACISTS' KNOWLEDGE AND PERCEPTION REGARDING DIETARY SUPPLEMENTS IN PALESTINE: DESCRIPTIVE STUDY
}

\author{
ABDEL A. QAWASMEH'1 , BESSAN YAGHI ${ }^{1}$, ALAA KHRAIWESH ${ }^{1}$ \\ ${ }^{1}$ Department of Pharmacy, Faculty of Pharmacy and Medical Sciences, Hebron University, Hebron, Palestine \\ Email: abedq@hebron.edu
}

Received: 08 Jul 2020, Revised and Accepted: 15 Aug 2020

\section{ABSTRACT}

Objective: To assess pharmacists' knowledge with regards registered dietary supplements DS and their perception toward DS registration by the ministry of health $\mathrm{MOH}$

Methods: A questionnaire was designed to assess pharmacists' knowledge about newly registered food supplements (registered after 2012) and to assess their view about the current measures followed by MOH in registering these supplements. The questionnaire was distributed to pharmacists in West Bank-Palestine during the period from December 2017 to March 2018. Data collected were analyzed using the Statistical Package for Social Sciences program (SPSS) version 10.

Results: Pharmacists' knowledge with regards to registered DS was high with approximately $86 \%$ have recorded the right answers. Their perception about the current increasing registration of DS, pharmacists (67\%) thinks that 'what available DS in the market' is enough and there is no need for more DS to be registered. Almost half of the pharmacists (48\%) think that the information provided regarding dietary supplements is inadequate and almost $30 \%$ think is adequate. More than $70 \%$ of the pharmacists they never or rarely access the MOH web site to access for information about DS.

Conclusion: This study highlighted the importance of controlling DS registration by the MOH and the necessity to effectively update pharmacists about these DS for effective counseling.

Keywords: Dietary supplements, Pharmacists knowledge, Palestine, Perception

(C) 2020 The Authors. Published by Innovare Academic Sciences Pvt Ltd. This is an open access article under the CC BY license (http://creativecommons.org/licenses/by/4.0/) DOI: http://dx.doi.org/10.22159/ijpps.2020v12i9.38975. Journal homepage: https://innovareacademics.in/journals/index.php/ijpps.

\section{INTRODUCTION}

Dietary supplements [1] are defined by the US Food and Drug Administration (FDA) as any product intended for ingestion to add further nutritional value to conventional food [2]. Dietary supplements come in a variety of forms including tablets, capsules, powders, and solutions. Popular supplements in the market include vitamins; minerals; herbs and some specialty supplements such as fibers, glucosamine, probiotics, and fish oils [2].

Vitamins, minerals, amino acids, enzymes, fibers, and herbal supplements sold in Palestine have been classified and registered by the Ministry of Health under the category of 'dietary supplements' [3]. Since 2012, the number of DS registered in Palestine has increased over the years, with now more than 290 products have been registered [3] and available to consumers. Such an increase has resulted in growing numbers of consumers seeking information about the use, effectiveness, and possible side effects of DS.

Registered DS are sold strictly in community pharmacies dispensed either as over-the-counter medications or by medical scripts. Accordingly, pharmacists need to be aware and updated about all available and newly registered DS to provide effective counseling and dispensing protocols. Registered pharmacists from many countries including Palestine have consistently expressed their need for more knowledge and training in the field of dietary supplements and herbal drugs to cope with growing consumers' concerns about DS [4-6]. Several studies have been designed to assess pharmacists' knowledge and their perception towards dietary supplements in many countries such as Kuwait [7], Saudi Arabia [8], Singapore [9], USA [1, 10], Canada [10], Australia [5], including Palestine [4, 11, 12]. These studies have focused on assessing pharmacists' knowledge regarding the indications, side effects, and pharmacological actions of particular medicinal plants thought to be sold in pharmacies [12].

Despite previous reports assessing pharmacists' knowledge with regards to herbal drugs sold in Palestine $[4,11]$, these studies were limited by the fact that they have assessed pharmacists' knowledge on common herbal plants that often do not exist in dosage forms in Palestinian pharmacies. Accordingly, this study was specifically designed to assess community pharmacists' knowledge regarding registered DS present in dosage forms and sold in Palestinian pharmacies, as well as their perception towards the ongoing process of DS registration by $\mathrm{MOH}$.

\section{MATERIALS AND METHODS}

\section{Study design, settings and study subjects}

This cross-sectional study was designed to assess pharmacists knowledge and their perception regarding DS and/or their registration by $\mathrm{MOH}$ in Palestine. The study was conducted in West Bank-Palestine in the cities of Jerusalem, Ramallah (middle) Hebron, Bethlehem (south), Jenin, Qalqilya, and Nablus (north) and commenced on Dec 2016 till March 2017. A total of 181 pharmacists randomly selected were recruited in the study. All pharmacists recruited in this study were registered Palestinian pharmacists, own a community pharmacy, or employed as a full-time community pharmacist. Pharmacists working in industrial, clinical settings, and/or in academia with no retail experiences were excluded from this study.,

\section{Questionnaire}

The questionnaire constructed and designed based on the questionnaire reported by Khdour et al., (2018) with modifications to specifically address pharmacists' knowledge and perception with regards to newly registered DS by the Palestinian $\mathrm{MOH}$. The questionnaire was divided into three sections, with section one contains information about pharmacists' demographic information, section two contained nine multiple-choice questions to assess pharmacists' knowledge regarding newly registered DS available in the market, and section 3 contained six statements to explore pharmacists' perception towards DS registration in Palestine. To evaluate pharmacists' knowledge about newly registered DS, nine 
different newly registered food supplements (registered after 2015) namely New-Fe-Folic, Reprovit, Herbalis-B, Vitex life, Milk thistle, DMax, New Nac, Cartina, NT-OX, were selected and multiple-choice questions about their therapeutic use, ingredients, manufacturer, strength, and/or the dosage form were asked. In the third section of the questionnaire, participants were presented with a list of questions related to drugs registered as DS available in the market, the role of $\mathrm{MOH}$ in registering DS, and the information available to pharmacists about these DS.

The questionnaire was constructed using Google drive and the final version was printed out and handed in person to community pharmacists. To check for readability and understanding the questionnaire was handed to ten community pharmacists from different educational levels and geographical locations. Their comments were considered before distributing the final questionnaire version.

The data obtained from the collected questionnaire were analyzed using the SPSS software version 21 (IBM, New York). Data for pharmacists' knowledge were categorized into two groups; not correct grouped as ' 1 ' or correct grouped as ' 2 ' and an independent- samples T-test and ANOVA was performed for analysis of responders' gender, age, employment status, education level, and area of practice. When the $p$-value was less than 0.05 considered to represent a statistically significant difference. Data related to pharmacists' perceptions were categorized into five different groups; strongly disagree ' 1 ', disagree ' 2 ', neutral ' 3 ', agree ' 4 ', strongly agree ' 5 '.

\section{RESULTS}

\section{Demographic information}

One hundred and eighty-one registered pharmacists in PalestineWest Bank were responded to the survey and all of them were included in the analysis. The demographic information of the pharmacists was summarized in (table 1). Of the 181 pharmacists, $96(53 \%)$ were females and $85(47 \%)$ were males. A $104(57 \%)$ of the pharmacists were at the ages between 20-30 y old. Most of the pharmacists $99(55 \%)$ had a full-time position in community pharmacies and the majority of pharmacists $136(75 \%)$ had a bachelor's degree in pharmacy, with almost $70 \%$ recruited pharmacists were graduated from national and Arab universities.

Table 1: Demographic information for participated pharmacists

\begin{tabular}{lll}
\hline Gender & Male & $85(47)$ \\
Age group (year) & Female & $96(53)$ \\
& $20-30$ & $54(57)$ \\
& $30-40$ & $16(9)$ \\
Employment status & $40-50$ & $7(5)$ \\
& $>50$ & $99(55)$ \\
Education & Full-time & $82(45)$ \\
& Part-time & $136(75)$ \\
& BSc & $19(10)$ \\
Country of graduation & Pharm-D & $21(12)$ \\
& Master & $5(3)$ \\
Area of practice & PhD & $93(51)$ \\
& Palestine & $35(19)$ \\
& Jordan & $17(10)$ \\
\hline
\end{tabular}

\section{Pharmacist knowledge}

Overall, pharmacists showed good knowledge regarding registered DS with almost $71 \%$ recorded the right answers. The range in percentage of correct answers to the questions provided was $43-92 \%$ with question one related to the "ingredients present in the DS New-Fe-Folic" showed the lowest percentage $43.6 \%$ (table 2) and question three "The dosage form of Herbalis-B is" scored the highest correct percentage $92.3 \%$.

Table 2: Pharmacists' knowledge toward registered dietary supplements marketed in palestinian pharmacies $(\mathrm{n}=181)$

\begin{tabular}{llll}
\hline$\#$ & Questions & 1 (No, \%) & 2 (No, \%) \\
\hline 1 & What are the ingredients present in New-Fe-Folic & $102(56.4 \%)$ & $79(43.6 \%)$ \\
2 & The manufacture of Reprovit is & $42(23.2 \%)$ & $139(76.8 \%)$ \\
3 & The dosage form of Herbalis-B is & $14(7.7 \%)$ & $167(92.3 \%)$ \\
4 & The dosage form of Vitex life is & $81(44.7 \%)$ & $100(55.2 \%)$ \\
5 & Milk thistle is mainly used for & $35(19.3 \%)$ & $146(80.6 \%)$ \\
6 & The dosage form of D-Max is & $82(45.3 \%)$ & $99(54.7 \%)$ \\
7 & The strength of n-acetylcysteine in New NAC is mg? & $22(12.1 \%)$ & $159(87.8 \%)$ \\
8 & An alternative drug of Cartia is & $29(16 \%)$ & $152(83.9 \%)$ \\
9 & The main ingredients in NT-OX caplets are & $59(32.6 \%)$ & $122(67.4 \%)$ \\
\hline
\end{tabular}

Pharmacists' knowledge significantly $(\mathrm{P}<0.05)$ affected by the area of practice. The average for correct answers scored by pharmacists in the north was 1.82 , and in the middle was 1.79 and both were significantly higher compared with south 1.68.

\section{Pharmacist perception}

According to the Pharmacists' views about the current measures followed by $\mathrm{MOH}$ in registering DS. A 47\% of the pharmacists thought that the registered DS in the market are enough, with only $24 \%$ thought that are not enough. The majority of pharmacists $68 \%$ 'strongly agree' and 'agree' that $\mathrm{MOH}$ should register more DS and a $42 \%$ of the pharmacists 'strongly agree' and 'agree' that newly registered food supplements are necessary for public health. A $45 \%$ of the pharmacists thought that communication with MOH is effective regarding DS. A 43\% of the pharmacists thought that there is a lack of information such as indication, side effect, and activity of newly registered DS. Approximately $71 \%$ of the pharmacists rarely or never access the MOH website seeking knowledge about newly registered DS (table 3). 
Table 3: Pharmacists' perception about dietary supplements registration

\begin{tabular}{|c|c|c|c|c|c|c|c|}
\hline \# & Questions & 1 & 2 & 3 & 4 & 5 & Mean (SD) \\
\hline 1 & $\begin{array}{l}\text { Do you think the market has enough drugs } \\
\text { registered as food supplements }\end{array}$ & $28(15.5 \%)$ & $15(8.3 \%)$ & $52(28.7 \%)$ & $39(21.5 \%)$ & 47 (25.9\%) & $3.34(1.36)$ \\
\hline 2 & $\begin{array}{l}\text { Do you think the MOH should register more drugs } \\
\text { as food supplements }\end{array}$ & $8(4.4 \%)$ & 17 (9.4\%) & $33(18.2 \%)$ & $81(44.7 \%)$ & $42(23.2 \%)$ & $3.73(1.06)$ \\
\hline 3 & $\begin{array}{l}\text { Newly registered food supplements are necessary } \\
\text { for public health }\end{array}$ & $12(6.63 \%)$ & $28(15.5 \%)$ & $65(35.9 \%)$ & $50(27.6 \%)$ & $26(14.4 \%)$ & $3.28(1.10)$ \\
\hline 4 & $\begin{array}{l}\text { Do you think the communication with } \mathrm{MOH} \text { is } \\
\text { effective regarding the food supplements }\end{array}$ & $30(16.6 \%)$ & $28(15.5 \%)$ & $42(23.2 \%)$ & $60(33.1 \%)$ & $21(11.6 \%)$ & 3.08 (1.27) \\
\hline 5 & $\begin{array}{l}\text { Do you think there is a lack in information about } \\
\text { newly registered food supplements, indications, } \\
\text { side effects }\end{array}$ & $26(14.4 \%)$ & $29(16 \%)$ & $49(27.1 \%)$ & $62(34.3 \%)$ & $15(8.3 \%)$ & 3.06 (1.19) \\
\hline 6 & $\begin{array}{l}\text { Do you access the } \mathrm{MOH} \text { web site to get details } \\
\text { about registered food supplements }\end{array}$ & $100(55.2 \%)$ & 27 (14.9\%) & 27 (14.9\%) & 17 (9.4\%) & $10(5.5 \%)$ & $1.95(1.26)$ \\
\hline
\end{tabular}

\section{DISCUSSION}

The majority of pharmacists $(>70 \%)$ in Palestine have reported to dispense and provide counseling about DS [11]. Such percentage has increased since 2013 due to their ability to treat a wide range of chronic and terminal diseases, the increased demands on DS by the public, and also the ongoing process of registration of new DS leading to an increase in the numbers and the variety of DS. In this study, all recruited pharmacists from 181 different pharmacies located in various cities in Palestine reported dispensing DS. Most DS in Palestine are imported with manufacturers and/or importers of DS are often excluded from many regulations and details that normally are associated with conventional therapy registration. Accordingly, pharmacists, since they are the primary provider for DS, are obligated to have an excellent up-to-date knowledge with regards to DS.

Pharmacists are a key source of information for patients seeking guidance about the use, safety, and efficacy of DS [13-15]. This study was the first to assess pharmacists' knowledge with regards to DS that have been registered and sold in Palestine. Pharmacists, overall, showed a good level of knowledge regarding registered DS $(>70 \%$ of the pharmacists have answered questions 2-9 correctly). Such good knowledge can be attributed to a limited number of registered DS (180 products) sold in the market at the time of conducting this study, the $1440 \mathrm{~h}$ pharmacy training, as well as the knowledge gained by studying courses such as pharmacognosy and phytochemistry during their studies. It is worth noting that these courses are mandatory in all Palestinian universities as well as in most Arab universities and have been eliminated from many universities around the world [16, 17]. Previous studies carried out to assess pharmacists' knowledge with regards to herbal drugs in Palestine $[4,11,12]$ were designed to address pharmacists' knowledge with regards the use, side effects, herb-drug interactions of herbal plants that often did not have any dosage forms registered in Palestine at the time have been carried out.

Pharmacists' knowledge was significantly affected by the area of practice. Pharmacists in the north and middle showed a significantly higher level of knowledge with regards to DS compared with the south. Pharmacists in Palestine appear to rely heavily on companies' representatives' visits to their pharmacies to get information about DS and to lesser extend on depending on what has been written on the package of the DS. The major factors contributing to lesser knowledge in DS among the pharmacists in southern cities include the fact that major governmental bodies including $\mathrm{MOH}$ and pharmaceutical companies are located in the middle and northern cities, the difference in the socioeconomic status of the population, and the difference in the intensity of the promotion for DS between the various parts of Palestine.

Nowadays, it has become common practice in Palestine not to dispense or provide effective counseling regarding scripts from doctors containing newly registered DS. Such a problem is more evident in rural pharmacies than urban pharmacies likely due to the variations in DS companies' promotional behaviors. In this study, pharmacists in Palestine $(>70 \%)$ rarely accessed the MOH web site seeking information about DS. Information such as therapeutic activity recommended daily dose, possible side effects, indications, and contraindications are not included in the $\mathrm{MOH}$ web site and often not provided with DS package. MOH usually provides up-todate information about DS trade name, date of registration, active ingredients, dosage form, and manufacturer and/or distributor. Such information could be of little impact during pharmacist' counseling and this could be a major factor why most Palestinian pharmacists showed little interest in finding information about registered DS using the $\mathrm{MOH}$ web site. Similar trends showing the lack of reliable sources of information regarding DS have been reported in the USA $[18,19]$ and Saudi Arabia [20]. Therefore, pharmacists' knowledge could decline in near future due to the ongoing and uncontrolled registration process of new DS by $\mathrm{MOH}$ continues, not including useful information about newly registered DS on MOH web site, and not improving the marketing policies of the newly registered DS.

Limitations of this study include the fact that pharmacists' knowledge and perception were assessed at a single-time-point where a limited number of registered DS was available at the time of conducting the study. So caution must be taken when interpreting these results. Moreover, the 181 community pharmacists from different pharmacies were randomly selected. These represent $19.2 \%$ of the total accessible pharmacies in Palestine. Such sample size may not representative of the whole pharmacists and a larger sample size may be needed. Despite these limitations, this study reflects the importance of providing, educating, and keeping community pharmacists updated about registered DS to provide effective counseling and patient care.

\section{CONCLUSION}

Community pharmacists in Palestine should be effectively informed about newly registered DS. Accordingly, $\mathrm{MOH}$ and companies' representatives collaboratively should provide comprehensive information to community pharmacists regarding the newly registered DS for better dispensing and counseling protocols in Palestinian pharmacies.

\section{ACKNOWLEDGMENT}

The authors thank all participating pharmacists.

\section{FUNDING}

This research has received no fund from any funding agency or any organization.

\section{AUTHORS CONTRIBUTIONS}

$\mathrm{AQ}$ and $\mathrm{BY}$ designed the questionnaire in collaboration with $\mathrm{AK}$, who made the analysis. AQ drafted the article and all other authors have revised it. All authors have read the final version and approved it. AQ and AK have full access to all related data.

\section{CONFLICTS OF INTERESTS}

The Author(s) declare(s) that they have no conflicts of interest to disclose. 


\section{REFERENCES}

1. Clauson KA, McQueen CE, Shields KM, Bryant PJ. Knowledge and attitudes of pharmacists in Missouri regarding natural products. Am J Pharm Edu 2003;67:1-9.

2. Umhau JC, Garg K, Woodward AM. Dietary supplements and their future in health care: commentary on draft guidelines proposed by the food and drug administration. Antioxid Redox Signal 2012;16:461-2.

3. Palestinian Ministry of Health. Available from: http://pharmacy.moh.ps/index/RegisteredProducts/language /ar2018 [Last accessed on 08 Jul 2020]

4. Khdour MR, Kurdi M, Hallak HO, Jarab AS, Dweib M, Al-Shahed QN. Pharmacists' knowledge, attitudes and practices towards herbal remedies in West Bank, Palestine. Inter Arch Med 2016;9:1-9.

5. Naidu S, Wilkinson JM, Simpson MD. Attitudes of Australian pharmacists toward complementary and alternative medicines. Ann Pharmacother 2005;39:1456-61.

6. Volmer D, Lilja J, Hamilton D, Bell JS, Veski P. Self-reported competence of Estonian community pharmacists in relation to herbal products: findings from a health-system in transition. Phytother Res 2011;25:381-6.

7. Abahussain NA, Abahussain EA, Al-Oumi FM. Pharmacists' attitudes and awareness towards the use and safety of herbs in Kuwait. Pharm Pract (Granada) 2007;5:125-9.

8. Alkharfy KM. Community pharmacists' knowledge, attitudes and practices towards herbal remedies in Riyadh, Saudi Arabia. East Mediterr Health J 2010;16:988-93.

9. Koh HL, Teo HH, Ng HL. Pharmacists' patterns of use, knowledge, and attitudes toward complementary and alternative medicine. J Altern Complement Med 2003;9:51-63.

10. Kwan D, Hirschkorn K, Boon HUS. Canadian pharmacists' attitudes, knowledge, and professional practice behaviors toward dietary supplements: a systematic review. BMC Complement Altern Med 2006;6:31.
11. Sweileh WM, Abu Arrah EM, Abu-Taha AS, Sawalha AF, Salah $\mathrm{OA}$, Jamous RM, et al. Pharmacists' dispensing practices, attitudes and knowledge towards herbal products in Palestine. Ibnosina J Med Biomed Sci 2013;5:123-30.

12. Shraim NY, Shawahna R, Sorady MA, Aiesh BM, Alashqar GS, Jitan RI, et al. Community pharmacists' knowledge, practices and beliefs about complementary and alternative medicine in palestine: a cross-sectional study. BMC Complement Altern Med 2017;17:429.

13. Djunaeid M, Azhar Syed Sulaiman S. The pharmacist's assessment on patients who consume supplements and herbal while undergoing warfarin therapy. Asian J Pharm Clin Res 2018;11:49-54

14. Dol HS, Shinde VR, Mali JV, Khakal NN. Pharmacovigilance: a practical approach for reshaping patient safety. Innovare J Med Sci 2017;5:1-4

15. Zulkifli NW, Aziz NA, Hassan Y, Hassali MA, Bahrin NLZ. Do current awareness and educational program towards unregistered drugs effective for public? Pharmacists' perceptive. Inter J Pharm Pharm Sci 2016;8:81-5.

16. Sekar MC, Taylor A. Should "Medicinal Herbs" be a mandatory course for pharmacy students? Modern Appl Pharm Pharmacol 2018;2:1-3.

17. Kouzi SA. Herbal remedies: the design of a new course in pharmacy. Am J Pharm Edu 1996;60:358-64.

18. Zeolla MM, Cerulli J. Use of and familiarity with dietary supplement information references by practicing pharmacists. J Am Pharm Assoc 2003;48:401-4.

19. Nathan JP, Cicero LA, Koumis T, Rosenberg JM, Feifer S, Maltz F. Availability of and attitudes toward resources on alternative medicine products in the community pharmacy setting. J Am Pharm Assoc 2003;45:734-9.

20. Al-Arifi MN. Availability and needs of herbal medicinal information resources at a community pharmacy, Riyadh region, Saudi Arabia. Saudi Pharm J 2013;21:351-60. 